\title{
Equilibrative Nucleoside Transporter 1 (ENT1, SLC29A1) Facilitates Transfer of the Antiretroviral Drug Abacavir across the Placenta
}

\author{
[- Lukas Cerveny, ${ }^{1}$ Zuzana Ptackova, ${ }^{1}$ Martina Ceckova, Rona Karahoda, Sara Karbanova, \\ Lucie Jiraskova, Susan L. Greenwood, Jocelyn D. Glazier, and ๑Frantisek Staud
}

Department of Pharmacology and Toxicology, Faculty of Pharmacy in Hradec Kralove, Charles University, Hradec Kralove, Czech Republic (L.C., Z.P., M.C., R.K., S.K., L.J., F.S.) and Maternal and Fetal Health Research Centre, Institute of Human Development, University of Manchester, St. Mary's Hospital, Central Manchester, University Hospitals NHS Foundation Trust, Manchester

Academic Health Science Centre, Manchester, United Kingdom (S.L.G., J.D.G.)

Received June 24, 2018; accepted August 8, 2018

\section{ABSTRACT}

Abacavir is a preferred antiretroviral drug for preventing mother-tochild human immunodeficiency virus transmission; however, mechanisms of its placental transfer have not been satisfactorily described to date. Because abacavir is a nucleoside-derived drug, we hypothesized that the nucleoside transporters, equilibrative nucleoside transporters (ENTs, SLC29A) and/or $\mathrm{Na}^{+}$-dependent concentrative nucleoside transporters (CNTs, SLC28A), may play a role in its passage across the placenta. To test this hypothesis, we performed uptake experiments using the choriocarcinoma-derived BeWo cell line, human fresh villous fragments, and microvillous plasma membrane (MVM) vesicles. Using endogenous substrates of nucleoside transporters, $\left[{ }^{3} \mathrm{H}\right]$-adenosine (ENTs, CNT2, and CNT3) and $\left[{ }^{3} \mathrm{H}\right]$-thymidine (ENTs, CNT1, and CNT3), we showed significant activity of ENT1 and CNT2 in BeWo cells, whereas experiments in the villous fragments and MVM vesicles, representing a model of the apical membrane of a syncytiotrophoblast, revealed only ENT1 activity. When testing $\left[{ }^{3} \mathrm{H}\right]$-abacavir uptakes, we showed that of the nucleoside transporters, ENT1 plays the dominant role in abacavir uptake into placental tissues, whereas contribution of $\mathrm{Na}^{+}$-dependent transport, most likely mediated by CNTs, was observed only in BeWo cells. Subsequent experiments with dually perfused rat term placentas showed that Ent1 contributes significantly to overall $\left[{ }^{3} \mathrm{H}\right]$-abacavir placental transport. Finally, we quantified the expression of SLC29A in first- and third-trimester placentas, revealing that SLC29A1 is the dominant isoform. Neither SLC29A1 nor SLC29A2 expression changed over the course of placental development, but there was considerable interindividual variability in their expression. Therefore, drug-drug interactions and the effect of interindividual variability in placental ENT1 expression on abacavir disposition into fetal circulation should be further investigated to guarantee safe and effective abacavir-based combination therapies in pregnancy.

\section{Introduction}

Mother-to-child transmission is the most common route of HIV infection in children. The risk of vertical HIV transmission can be minimized by perinatal administration of a combination antiretroviral therapy that suppresses viral replication in maternal blood and genital secretions. It has recently been emphasized that combination antiretroviral therapy should include an antiretroviral drug with high placental transfer for pre-exposure prophylaxis of the fetus (http://aidsinfo.nih. gov/contentfiles/lvguidelines/PerinatalGL.pdf).

The functional part of the placental barrier is the polarized multinucleated syncytiotrophoblast, which expresses various carriers, including equilibrative nucleoside transporters (ENTs) (Staud et al., 2012). ENTs are ubiquitously occurring proteins belonging to the solute carrier (SLC)

This project was financially supported by the Czech Science Foundation [Grant GACR 17-16169S] and Charles University in Prague [Grants GAUK 324215/C/ 2015, 812216/C/2016, and SVV/2017/260 414].

${ }^{1}$ L.C. and Z.P. contributed equally to this work.

https://doi.org/10.1124/dmd.118.083329. transporter superfamily that mediate bidirectional facilitated diffusion of nucleosides in tissues to maintain nucleoside homeostasis (MolinaArcas et al., 2009). Beyond their physiologic role, ENTs, especially the two important isoforms ENT1 and ENT2 (Griffiths et al., 1997), affect the pharmacokinetics of a broad array of nucleoside-derived drugs, including nucleoside reverse transcriptase inhibitors (didanosine and zalcitabine), antihepatitis therapeutics (ribavirin and entecavir), or antineoplastic drugs (gemcitabine and cladribine) (Yamamoto et al., 2007; Molina-Arcas et al., 2009; Ma et al., 2017). Both ENT1 (encoded by SLC29A1) and ENT2 (encoded by SLC29A2) are transcribed in the human syncytiotrophoblast (Govindarajan et al., 2007; Yamamoto et al., 2007; Errasti-Murugarren et al., 2011). ENT1 has been detected in the maternalfacing (apical) microvillous plasma membrane of the syncytiotrophoblast, whereas ENT2 is localized on both the apical and fetal-facing (basal) plasma membrane (Barros et al., 1995; Govindarajan et al., 2007; ErrastiMurugarren et al., 2011). ENT1-like activity has also been observed on the syncytiotrophoblast basal plasma membrane despite undetectable ENT1 expression at this locus (Errasti-Murugarren et al., 2011).

Other than ENTs, placental expression of concentrative nucleoside transporters (CNTs, SLC28A) that mediate unidirectional $\mathrm{Na}^{+}$-dependent

ABBREVIATIONS: ABCB1, P-glycoprotein; ABCG2, breast cancer resistance protein; BCA, bicinchoninic acid; BeWo, choriocarcinoma-derived cell line; CNT, concentrative nucleoside transporter; ENT, equilibrative nucleoside transporter; $F \rightarrow M$, fetal-to-maternal clearance; $h$, human; $M \rightarrow F$, maternal-to-fetal clearance; MVM, microvillous plasma membrane; NBMPR, $\mathrm{S}^{6}$-(4-nitrobenzyl)mercaptopurine riboside; PCR, polymerase chain reaction; $r$, rat; SLC, solute carrier. 
influx of nucleosides and nucleoside analogs (Molina-Arcas et al., 2009) has also been suggested, although with conflicting results. Whereas Errasti-Murugarren et al. (2011) observed protein expression of CNT1 despite very low mRNA expression, Govindarajan et al. (2007) did not detect protein expression of CNTs in the term placenta. In addition, Barros et al. (1991) demonstrated that there is no effect of $\mathrm{Na}^{+}$depletion on nucleoside uptake into microvillous plasma membrane (MVM) vesicles.

The expression of drug transporters in the placenta frequently varies during gestation and differs among individuals (Gil et al., 2005; Mao, 2008; Ahmadimoghaddam et al., 2013). This holds true also for SLC28A, exhibiting significant interindividual variability and higher expression in the term placenta compared with the first trimester (Jiraskova et al., 2018); however, such data are lacking for SLC29A.

Abacavir is a nucleoside analog belonging to the family of nucleoside reverse-transcriptase inhibitors. It is currently a preferred anti-HIV compound for mother-to-child transmission prevention (http://aidsinfo. nih.gov/contentfiles/lvguidelines/PerinatalGL.pdf). Transplacental transfer of abacavir in humans has been investigated only sparsely, and its cord-to-maternal-blood concentration ratio is variable, ranging from $62 \%$ to $163 \%$ at term (Chappuy et al., 2004; Best et al., 2006; Fauchet et al., 2014). The pharmacokinetics of antiviral drugs are frequently affected by the activity of drug transporters (Kis et al., 2010; Neumanova et al., 2014, 2015, 2016; Ceckova et al., 2016). Abacavir is a known substrate of P-glycoprotein (ABCB1) and breast cancer resistance protein (ABCG2) (Shaik et al., 2007; Giri et al., 2008; Neumanova et al., 2015), and we recently demonstrated that these transporters may limit abacavir maternal-to-fetal transfer (Neumanova et al., 2015). Importantly, abacavir was reported to reduce nucleoside uptake in vitro, raising the possibility that abacavir is also a substrate for ENTs (Hong et al., 2000; Li et al., 2015).

Because a detailed understanding of drug interactions with placental transporters is required to guarantee safe and effective therapy during pregnancy (Staud et al., 2012; Thomas and Yates, 2012; Staud and Ceckova, 2015), we sought to determine whether ENTs play a role in the transplacental transfer of abacavir. We analyzed abacavir uptake into the placental choriocarcinoma-derived cell line BeWo and fresh villous placental fragments and MVM vesicles, both derived from the human term placenta. We then performed in situ dual-perfusion studies in the rat term placenta to quantify the role of ENTs in total transplacental abacavir clearance. In all experimental models, we also considered the potential contribution of CNTs to abacavir placental kinetics. Finally, using a quantitative polymerase chain reaction (PCR) method, we investigated the expression of SLC29A1 and SLC29A2 and their interand intraindividual variability in the first- and third-trimester human placenta.

\section{Material and Methods}

Chemicals and Reagents. The radiolabeled compounds $\left[{ }^{3} \mathrm{H}\right]$-abacavir $(0.05$ or $0.1 \mathrm{Ci} / \mathrm{mM}),\left[{ }^{3} \mathrm{H}\right]$-adenosine $(23 \mathrm{Ci} / \mathrm{mM})$, and $\left[{ }^{3} \mathrm{H}\right]$-thymidine $(74 \mathrm{Ci} / \mathrm{mM})$ were purchased from Moravek Biochemicals (Brea, $\mathrm{CA}$ ); adenosine represents a model substrate of ENT1, ENT2, CNT2, and CNT3, whereas thymidine is transported by ENT1, ENT2, CNT1, and CNT3 (Molina-Arcas et al., 2009). The specific ENT inhibitor $S^{6}$-(4-nitrobenzyl)mercaptopurine riboside (NBMPR) and the competitive inhibitors of ENTs and CNTs, uridine and adenosine (MolinaArcas et al., 2009; Errasti-Murugarren et al., 2011), were purchased from SigmaAldrich (St. Louis, MO); NBMPR $(0.1 \mu \mathrm{M})$ selectively inhibits human and rat ENT1/Ent1, whereas a concentration of $100 \mu \mathrm{M}$ abolishes the activity of both human and rat ENT1/Ent1 and ENT2/Ent2 (Chishu et al., 2008; Sai et al., 2008; Molina-Arcas et al., 2009; Nishimura et al., 2011, 2012; Karbanova et al., 2017). Pentobarbital (Nembutal) was purchased from Abbott Laboratories (Abbott Park, IL). Solvent dimethylsulfoxide was obtained from Sigma-Aldrich, and its volume/volume concentration was $0.1 \%$ in all experiments. All other chemicals were of analytical grade. Bicinchoninic acid (BCA) assay reagents were purchased from Thermo Scientific (Rockford, IL), and Bradford Reagents were purchased from Sigma-Aldrich.

Cell Lines. The human choriocarcinoma-derived BeWo cell line was purchased from the European Cell Culture Collection (Salisbury, Wiltshire, UK). Cells were cultured in Ham's F12 medium supplemented with $10 \%$ fetal bovine serum (Karbanova et al., 2017). The cells were cultured at $37^{\circ} \mathrm{C}$ under an atmosphere containing $5 \% \mathrm{CO}_{2}$.

Animals. Pregnant Wistar rats were purchased from MediTox s.r.o. (Konarovice, Czech Republic) and maintained under 12/12-hour day/night standard conditions with water and chow pellets ad libitum. Experiments were performed on day 21 of gestation (counted from the day when copulation plug was found). Overnight-fasted rats were anesthetized by administering a dose of $40 \mathrm{mg}$ of pentobarbital $/ \mathrm{kg}$ bodyweight (Nembutal; Abbott Laboratories) into the tail vein. All experiments were approved by the Ethical Committee of the Faculty of Pharmacy in Hradec Kralove (Charles University in Prague, Prague, Czech Republic) and were carried out in accordance with the Guide for the Care and Use of Laboratory Animals (2011) and the European Convention for the Protection of Vertebrate Animals Used for Experimental and Other Scientific Purposes.

Sample Collection of Human and Rat Placentas. Third-trimester placentas were obtained from uncomplicated pregnancies $(n=14)$ following elective cesarean section at term (between weeks 38 and 41 of gestation). First-trimester placentas $(n=7)$ were acquired from voluntary interruption of physiologically ongoing pregnancies between weeks 9 and 13 of gestation as described previously (Ahmadimoghaddam et al., 2013). All participants provided written informed consent. Rat term placentas were collected from five rats on day 21 of pregnancy $(n=5)$. The samples were frozen in liquid nitrogen immediately after surgery and then stored at $-80^{\circ} \mathrm{C}$ until analysis.

RNA Isolation and Reverse Transcription. Total RNA was isolated from weighed tissue samples or directly from BeWo cells using Tri-Reagent solution purchased from Molecular Research Centre (Cincinnati, OH) according to the manufacturer's instructions. The purity of the isolated RNA was checked by the A260/A280 ratio, and RNA integrity was confirmed by electrophoresis on 1\% agarose gel. The concentration of RNA was calculated by A260 measurement. RNA was converted into cDNA using the gb Reverse Transcription Kit from Generi Biotech s.r.o. (Hradec Kralove, Czech Republic) on a T100 Thermal Cycler (Bio-Rad, Hercules, CA).

Qualitative End-Point PCR Analysis. End-point PCR was carried out in BeWo cells and samples of rat/human term placentas to verify expression of target genes in our experimental models. cDNA (25 ng) was amplified in a $20-\mu \mathrm{l}$ reaction volume using MyTaq Red DNA Polymerase (cat. no. BIO-21108; Bioline, Taunton, MA) according to the manufacturer's instructions using a BioRad T100 Thermal Cycler. For amplification of human SLC29A1 and SLC29A2 in human placentas and BeWo cells, we used primers designed by Yamamoto et al. (2007) that provide amplicons of 512 and $470 \mathrm{bp}$, respectively (Yamamoto et al., 2007). PCR analysis of rat placental samples was performed using $5^{\prime}$ CCAAGAGGAGGAAGAGAGGAATC-3' and 5'-TAAAGAGGGAGGGCAGGTAGTG-3' as the forward and reverse primers, respectively, for SLC29A1, and 5'-CCCACAGACACCTTCAACTTCA-3' and 5'-GTGCTGTAGGTAGAAGGCATGGT- $3^{\prime}$ as the forward and reverse primers for $S L C 29 A 2$, providing amplicons of 400 and $302 \mathrm{bp}$, respectively. The PCR cycling conditions used were $95^{\circ} \mathrm{C}$ for 3 minutes followed by 50 cycles of $95^{\circ} \mathrm{C}$ for 30 seconds, $56^{\circ} \mathrm{C}$ for 30 seconds, and $72^{\circ} \mathrm{C}$ for 45 seconds, followed by 10 minutes at $72^{\circ} \mathrm{C}$. Amplicons were analyzed on $1.5 \%$ agarose gel labeled with GelRed Nucleic Acid Stain (Biotium, Hayward, CA) using the HyperLadderTM 100 bp DNA length marker (Bioline).

Quantitative PCR Analysis. Quantitative PCR analysis of SLC29A1 and $S L C 29 A 2$ expression in rat term placentas, BeWo cells, and first- and thirdtrimester human placentas was performed using QuantStudio 6 (Thermo Fisher Scientific, Waltham, MA). cDNA (25 ng) prepared from rat tissue and BeWo cells was analyzed in $20-\mu 1$ reaction volumes in a 96-well plate. Human placental cDNA (10 ng) was amplified in a 384-well plate, with total reaction volumes of $10 \mu 1$ per well. PCR was performed using the TaqMan Universal Master Mix II without uracil-DNA glycosylase (Thermo Fisher Scientific) and predesigned TaqMan Real Time Expression PCR assays for human $(h)$ or rat $(r) S L C 29 A 1$ (Hs01085704_g1c, Rn01648953_m1) and SLC29A2 (Hs00155426_m1, Rn01479421_m1). For greater precision during the mRNA quantification of 
target genes, data were normalized against the geometric mean of expression of two previously identified TaqMan housekeeping genes: $B 2 M$ (Hs00187842_m1) and GAPDH (Hs02758991_g1) for human samples, and Ywhaz (Rn00755072_m1) and Gapdh (Rn01775763_g1) for rat samples (Ahmadimoghaddam et al., 2013; Cerveny et al., 2016). Stable expression of both reference genes was verified before beginning the quantitative analysis. Each sample was amplified in triplicate using the following PCR cycling profile: $95^{\circ} \mathrm{C}$ for 3 minutes, followed by 40 cycles at $95^{\circ} \mathrm{C}$ for 15 seconds and $60^{\circ} \mathrm{C}$ for 60 seconds. Analyses of amplification efficiency (Pfaffl, 2001) for $S L C 29 A 1$ and SLC29A2 yielded values of $\approx 2$-fold increase per PCR cycle (data not shown), making it possible to compare the expression data for the two genes. Expression levels are reported in arbitrary units and were derived by normalizing the expression of the target gene against that of the reference genes (Radilova et al., 2009).

In Vitro Accumulation Studies in BeWo Cells. For uptake experiments, BeWo cells were seeded at a density of $3.5 \times 10^{5}$ on 24-well culture plates (TPP Techno Plastic Products, Trasadingen, Switzerland) and cultured for 3 days until confluence with daily medium replacement. Uptake experiments were performed as previously described, with modifications (Yamamoto et al., 2007; Karbanova et al., 2017). In brief, experiments were performed in $0.25 \mathrm{ml}$ of control $\left(\mathrm{Na}^{+}\right.$-containing) buffer $\left(140 \mathrm{mM} \mathrm{NaCl}, 5.4 \mathrm{mM} \mathrm{KCl}, 1.8 \mathrm{mM} \mathrm{CaCl}_{2}, 0.8 \mathrm{mM}\right.$ $\mathrm{MgSO}_{4}, 5 \mathrm{mM}$ glucose, and $25 \mathrm{mM}$ Tris) or $\mathrm{Na}^{+}$-free buffer $\left(\mathrm{Na}^{+}\right.$was replaced by $N$-methyl-D-glucamine). Two model substrates of nucleoside transporters, $\left[{ }^{3} \mathrm{H}\right]$ adenosine $(17.4 \mathrm{nM})$ and $\left[{ }^{3} \mathrm{H}\right]$-thymidine $(5 \mathrm{nM})$, were used as positive controls (Molina-Arcas et al., 2009) at a final activity of $0.4 \mu \mathrm{Ci} / \mathrm{ml}$. Time-dependent uptakes of $\left[{ }^{3} \mathrm{H}\right]$-adenosine $(17.4 \mathrm{nM}),\left[{ }^{3} \mathrm{H}\right]$-thymidine $(5 \mathrm{nM})$, and $\left[{ }^{3} \mathrm{H}\right]$-abacavir $(10 \mu \mathrm{M})$ in both $\mathrm{Na}^{+}$-containing and $\mathrm{Na}^{+}$-free buffers were assessed. Based on time-course data, the effect of NBMPR $(0.1$ or $100 \mu \mathrm{M})$ or uridine $(5 \mathrm{mM})$ as control inhibitors on $\left[{ }^{3} \mathrm{H}\right]$-adenosine $(17.4 \mathrm{nM})$ and $\left[{ }^{3} \mathrm{H}\right]$-abacavir $(10 \mu \mathrm{M})$ accumulation was subsequently evaluated over 5- and 1-minute intervals, respectively. Before the start of the experiment, cells were preincubated for 10 minutes in the respective buffer with or without the aforementioned inhibitors. Accumulation was stopped by quick aspiration of the radioactivity-containing buffer. Then, cells were washed twice with $0.75 \mathrm{ml}$ of buffer containing the appropriate inhibitor, after which the cells were lysed in $0.02 \%$ SDS. The intracellular concentrations of radioisotopes were determined and normalized against the protein content (Pierce BCA Protein Assay Kit; Thermo Fisher Scientific)

Ex Vivo Accumulation Studies in Fresh Villous Fragments from Human Placenta. Ex vivo analysis of $\left[{ }^{3} \mathrm{H}\right]$-abacavir uptake by the human placenta was performed using the method of accumulation in fresh villous fragments of human placentas at term (Atkinson et al., 2006; Greenwood and Sibley, 2006; Neumanova et al., 2015; Karbanova et al., 2017). In brief, placentas were collected at term after uncomplicated pregnancies (after 38-40 weeks of gestation) from women at St. Mary's Hospital (Manchester, UK) or from the University Hospital (Hradec Kralove, Czech Republic) after receiving the women's written informed consent as approved by the Local Research Ethics Committees (REC 12/NW/0574 and 201006S15P, respectively). Small fragments of villous tissue were dissected within 30 minutes of delivery, appropriately washed in either $\mathrm{Na}^{+}$-containing Tyrode's buffer $(135 \mathrm{mM} \mathrm{NaCl}, 5 \mathrm{mM} \mathrm{KCl}$, $1.8 \mathrm{mM} \mathrm{CaCl}_{2}, 1 \mathrm{mM} \mathrm{MgCl}, 10 \mathrm{mM}$ HEPES, $5.6 \mathrm{mM}$ glucose, $\mathrm{pH}$ 7.4) or $\mathrm{Na}^{+}-$ free Tyrode's buffer $\left(\mathrm{Na}^{+}\right.$was replaced by choline chloride), and then tied to hooks. Before the experiments, the fragments were stabilized for 30 minutes in a 1:1 mixture of $\mathrm{Na}^{+}$-containing or $\mathrm{Na}^{+}$-free Tyrode's buffer and Dulbecco's modified Eagle's medium $(4 \mathrm{ml})$. Initially, we determined the time courses of $\left[{ }^{3} \mathrm{H}\right]$-adenosine $(0.5 \mu \mathrm{Ci} / \mathrm{ml} ; 21.8 \mathrm{nM}),\left[{ }^{3} \mathrm{H}\right]$-thymidine $(0.5 \mu \mathrm{Ci} / \mathrm{ml} ; 6 \mathrm{nM})$, and $\left[{ }^{3} \mathrm{H}\right]$-abacavir $(0.5 \mu \mathrm{Ci} / \mathrm{ml}, 5 \mu \mathrm{M})$ uptakes in control buffer with/without NBMPR $(100 \mu \mathrm{M})$ or in the absence of $\mathrm{Na}^{+}$to confirm ENT and CNT activity in placental fresh villous fragments. Based on the time-course data, we next investigated the effect of selected inhibitors (NBMPR at 100 and $0.1 \mu \mathrm{M}$, or uridine at $5 \mathrm{mM}$ ) on $\left[{ }^{3} \mathrm{H}\right]$-adenosine and $\left[{ }^{3} \mathrm{H}\right]$-abacavir uptake after 5 minutes of incubation. To terminate accumulation and remove extracellularly bound isotope, fragments were vigorously washed twice in an excess of ice-cold Tyrode's buffer containing the appropriate inhibitor for 15 seconds. Villous fragments were subsequently stored in distilled water for 18 hours, and the quantity of radioisotope released was determined. The fragments were then removed from the water and dissolved in $0.3 \mathrm{M} \mathrm{NaOH}$ for 10 hours at $37^{\circ} \mathrm{C}$, after which fragment protein content was quantified using the Bradford protein assay (Bio-Rad). Finally, the $\mathrm{NaOH}$ lysate was analyzed for tissue-bound radioisotopes; samples were excluded from further analysis if the lysate's radioisotope content was above $1 \%$ of the amount of tracer added.

Preparation of MVM Vesicles and Uptake Assays. MVM vesicles were used to directly analyze the role of ENTs in $\left[{ }^{3} \mathrm{H}\right]$-abacavir transport across the apical plasma membrane of the human syncytiotrophoblast layer. Human placentas were obtained as described in the previous paragraph. MVM vesicles were isolated by $\mathrm{Mg}^{2+}$ precipitation and differential centrifugation (Glazier et al., 1988; Ceckova et al., 2016). The final MVM pellet was resuspended in intravesicular buffer $(290 \mathrm{mM}$ sucrose, $5 \mathrm{mM}$ HEPES, and $5 \mathrm{mM}$ Tris, pH 7.4), vesiculated by passing 15 times through a 25 -gauge needle, stored at $4{ }^{\circ} \mathrm{C}$, and used within 3 days of isolation or frozen at $-80^{\circ} \mathrm{C}$ and equilibrated to room temperature on the day of the experiment. Comparable uptake rate in fresh and thawed vesicles was verified before initiation of uptake experiments. The MVM protein concentration was determined using the BCA assay. Optimal purity was confirmed by measuring the enrichment of MVM alkaline phosphatase activity related to the placental homogenate, whereas vesicle orientation was evaluated by comparing specific alkaline phosphatase activity upon addition of detergent, as described previously (Glazier et al., 1988). The alkaline phosphatase enrichment factor was $25.2 \pm 6.39$ (mean \pm S.D., $n=8$ ), and percentage of physiologically orientated vesicles was $87.2 \% \pm 8.79 \%$, documenting that potential contamination of the MVM vesicles with basal plasma membrane and/or intracellular membranes was negligible (Glazier et al., 1988; Mahendran et al., 1994; Godfrey et al., 1998; Harrington et al., 1999), and thus, the quality of MVM vesicles was sufficient for functional study of apically localized placental ENTs and CNTs. Uptake of $\left[{ }^{3} \mathrm{H}\right]$-adenosine $(3.3 \mu \mathrm{Ci} / \mathrm{ml} ; 0.145 \mu \mathrm{M}),\left[{ }^{3} \mathrm{H}\right]$-thymidine $(3.3 \mu \mathrm{Ci} / \mathrm{ml}$; $1 \mu \mathrm{M})$, and $\left[{ }^{3} \mathrm{H}\right]$-abacavir $(0.5 \mu \mathrm{Ci} / \mathrm{ml} ; 5 \mu \mathrm{M})$ into MVM vesicles was measured at room temperature using a rapid vacuum filtration approach (Glazier and Sibley, 2006). MVM vesicles (10-20 mg protein/ml) were equilibrated to room temperature $\left(21^{\circ} \mathrm{C}-25^{\circ} \mathrm{C}\right)$ prior to uptake. Ten microliters of MVM was preincubated for 10 minutes with or without inhibitor $(0.1,100 \mu \mathrm{M}$ NBMPR; $1 \mathrm{mM}$ uridine; or $1 \mathrm{mM}$ adenosine) in extravesicular buffer (145 mM NaCl, $5 \mathrm{mM}$ HEPES, and $5 \mathrm{mM}$ Tris, $\mathrm{pH} 7.4$; for $\mathrm{Na}^{+}$-free buffer, $\mathrm{KCl}$ was used instead of $\mathrm{NaCl})$. Uptake of $\left[{ }^{3} \mathrm{H}\right]$-adenosine, $\left[{ }^{3} \mathrm{H}\right]$-thymidine, or $\left[{ }^{3} \mathrm{H}\right]$-abacavir was initiated by adding the substrate diluted in extravesicular buffer to the preincubated MVM vesicles. Uptake was halted after defined time points by adding $2 \mathrm{ml}$ of ice-cold stopping buffer ( $130 \mathrm{mM} \mathrm{NaCl}, 10 \mathrm{mM} \mathrm{Na}_{2} \mathrm{HPO}_{4}, 4.2 \mathrm{mM} \mathrm{KCl}, 1.2 \mathrm{mM} \mathrm{MgSO}_{4}$, $0.75 \mathrm{mM} \mathrm{CaCl} 2, \mathrm{pH}$ 7.4) with $100 \mu \mathrm{M}$ NBMPR where appropriate and subsequent filtering through a $0.45-\mu \mathrm{m}$ mixed cellulose ester filter (MFMillipore membrane filter HAWP02500; MilliporeSigma, Burlington, MA) under vacuum. Filters were washed with $10 \mathrm{ml}$ of stopping buffer, and the filter-associated radioactivity was determined. No protein controls (in which the MVM vesicle protein was replaced with intravesicular buffer) were analyzed in parallel to determine tracer binding to the filter, which was subtracted from the total vesicle count. Unspecific binding of all three compounds to the plasma membrane was excluded by measuring time zero uptakes, showing comparable values to the no-protein controls.

In Situ Dual Perfusion of the Rat Term Placenta. Transplacental transport of $\left[{ }^{3} \mathrm{H}\right]$-abacavir was measured using dually perfused rat term placentas in openand closed-circuit setups as described previously (Neumanova et al., 2014, 2015, 2016; Ceckova et al., 2016; Karbanova et al., 2017; Cerveny et al., 2018). At the end of each experiment, the placenta was perfused with radioactivity-free buffer for 10 minutes, then excised from the uterine tissue and dissolved in Solvable tissue solubilizer (PerkinElmer, Waltham, MA), after which tissue-bound $\left[{ }^{3} \mathrm{H}\right]$ abacavir was determined.

An open-circuit perfusion system was used to assess the effect of NBMPR $(0.1$ and $100 \mu \mathrm{M})$ or uridine $(5 \mathrm{mM})$ on maternal-to-fetal $(\mathrm{M} \rightarrow \mathrm{F})$ and fetal-to-maternal $(\mathrm{F} \rightarrow \mathrm{M})$ clearances of $\left[{ }^{3} \mathrm{H}\right]$-abacavir at an activity of $0.06 \mu \mathrm{Ci} / \mathrm{ml}$, corresponding to a concentration of $300 \mathrm{nM}$. The appropriate inhibitor was added to both reservoirs immediately after successful surgery, and $\left[{ }^{3} \mathrm{H}\right]$-abacavir was added to either the maternal $(\mathrm{M} \rightarrow \mathrm{F}$ studies $)$ or the fetal $(\mathrm{F} \rightarrow \mathrm{M}$ studies $)$ reservoir. After a 5-minute stabilization period, sample collection was started (this experimental time point was designated 0 minutes). Fetal effluent samples were collected at 5-minute intervals and placed in preweighed vials, after which $\left[{ }^{3} \mathrm{H}\right]$-abacavir concentration was determined and the transplacental clearance was calculated as described previously (Neumanova et al., 2014, 2015).

A closed-circuit (recirculation) perfusion system was used to further study the involvement of ENTs in transplacental abacavir transport. The maternal and fetal 


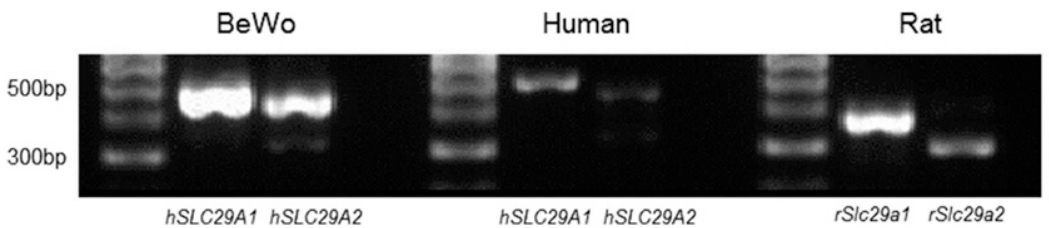

Fig. 1. End-point PCR analysis of $h S L C 29 A 1 / r S l c 29 a l$ and hSLC29A2/rSlc29a2 mRNA expression in BeWo cells and term human and rat placentas. The expected sizes of the PCR products were 512 bp for $h S L C 29 A 1,470$ bp for $h S L C 29 A 2,400 \mathrm{bp}$ for $r S l c 29 a 1$, and 302 bp for $r S l c 29 a 2$.

sides of the placenta were infused with equal concentrations of $\left[{ }^{3} \mathrm{H}\right]$-abacavir $(0.06 \mu \mathrm{Ci} / \mathrm{ml}, 300 \mathrm{nM})$. NBMPR $(0.1 \mu \mathrm{M})$ was then added into both compartments, and after a 5-minute stabilization period, the fetal perfusate $(10 \mathrm{ml})$ was recirculated for 60 minutes. Samples $(250 \mu \mathrm{l})$ were then collected every 10 minutes from the maternal and fetal reservoirs.

Radioisotope Analysis. The concentrations of $\left[{ }^{3} \mathrm{H}\right]$-adenosine, $\left[{ }^{3} \mathrm{H}\right]$ thymidine, and $\left[{ }^{3} \mathrm{H}\right]$-abacavir in experimental samples were measured by liquid scintillation counting (Tri-Carb 2910 TR; PerkinElmer). Tested concentrations of $\left[{ }^{3} \mathrm{H}\right]$-adenosine, $\left[{ }^{3} \mathrm{H}\right]$-thymidine, and $\left[{ }^{3} \mathrm{H}\right]$-abacavir differed among experimental procedures, as the lowest possible concentrations providing sufficient activity measurable in respective experimental systems were used; the low concentrations prevented transporter saturation, guaranteeing method sensitivity. The radioisotopes have been previously used to investigate their interactions with membrane transporters (Pan et al., 2007; Shaik et al., 2007; Chishu et al., 2008; Giri et al., 2008; Neumanova et al., 2015; Karbanova et al., 2017). The radioisotope quantitation of $\left[{ }^{3} \mathrm{H}\right]$-adenosine and $\left[{ }^{3} \mathrm{H}\right]$-thymidine is complicated by its extensive placental metabolism (Dancis et al., 1993; Acevedo et al., 1995). Since the major metabolites are not transported by ENTs (Osses et al., 1996), it can be assumed that these had a negligible impact on the uptake studies.

Statistical Analyses. Quantitative PCR data were processed using the nonparametric unpaired Mann-Whitney test or the parametric unpaired twotailed Student's $t$ test where appropriate. Results collected from accumulation studies in BeWo cells and dual-perfusion studies on rat placentas were processed by parametric unpaired two-tailed Student's $t$ test and one-way analysis of variance after a post hoc Dunnett's multiple comparison test. Uptake studies on fresh villous fragments and vesicles prepared from human placentas were analyzed using the nonparametric unpaired Kruskal-Wallis test following Dunn's multiple comparison test and multiple and nonparametric Wilcoxon matchedpairs signed rank tests, respectively. All statistical calculations were performed with GraphPad Prism 7.04 (GraphPad Software, La Jolla, CA).

\section{Results}

End-Point PCR Analysis of SLC29A1 and SLC29A2 mRNA Expression in BeWo Cells Human and Rat Term Placentas. We first confirmed the expression of SLC29A1 and SLC29A2 mRNA (encoding ENT1 and ENT2, respectively) in BeWo cells and human and rat term placentas. Amplicons specific for the primer pairs used (512 bp for $h S L C 29 A 1$ and $470 \mathrm{bp}$ for $h S L C 29 A 2$; $400 \mathrm{bp}$ for $r S l c 29 a 1$ and 302 bp for $r S l c 29 a 2$ ) were detected in all tested samples (Fig. 1).

In Vitro Investigation of Nucleoside Transporters' Role in $\left[{ }^{3} \mathbf{H}\right]$ Abacavir Uptake Using BeWo Cells. BeWo cells were used as a simple in vitro model of the placental barrier to investigate potential roles of ENTs and CNTs in the transplacental kinetics of abacavir. We first analyzed time-dependent uptake of $\left[{ }^{3} \mathrm{H}\right]$-adenosine $(17.4 \mathrm{nM}),\left[{ }^{3} \mathrm{H}\right]$ thymidine $(5 \mathrm{nM})$, and $\left[{ }^{3} \mathrm{H}\right]$-abacavir $(10 \mu \mathrm{M})$ (Fig. 2, A-C), showing a significant effect of $\mathrm{Na}^{+}$depletion on $\left[{ }^{3} \mathrm{H}\right]$-adenosine and $\left[{ }^{3} \mathrm{H}\right]$-abacavir.

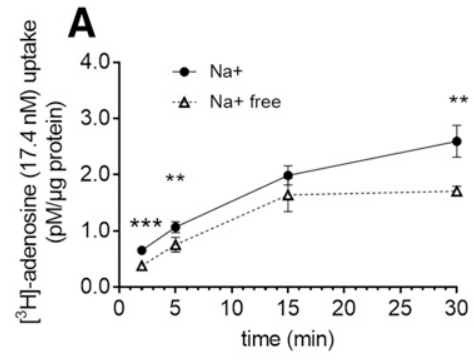

D

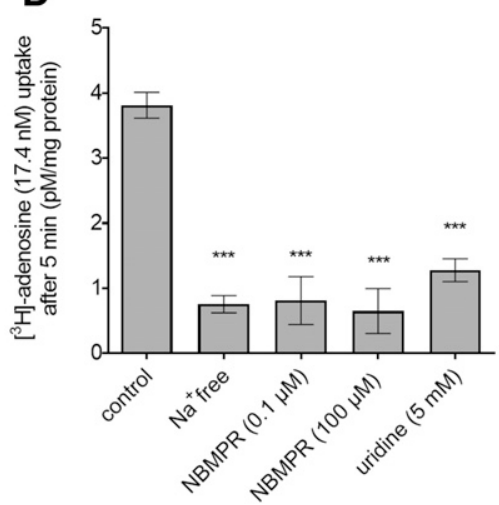

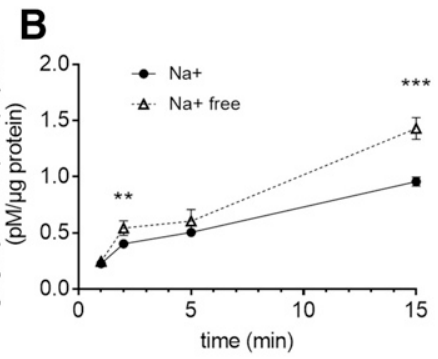

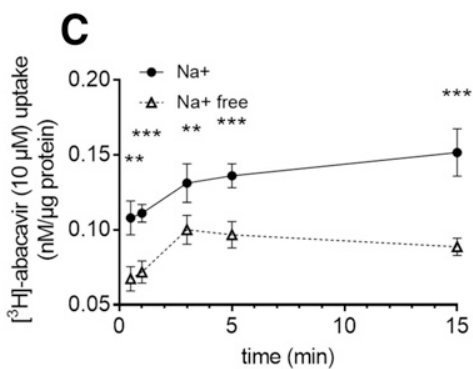

E

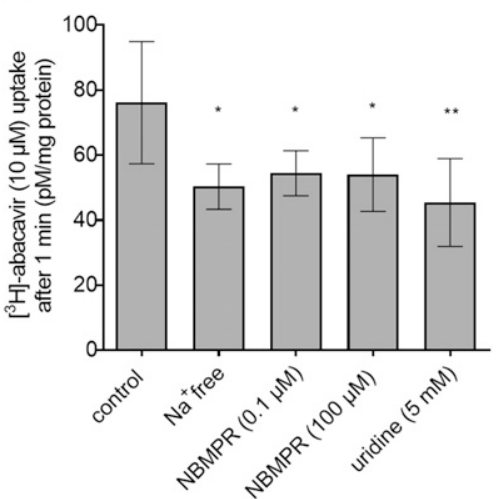

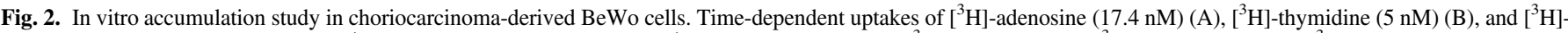

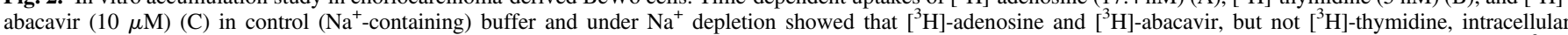

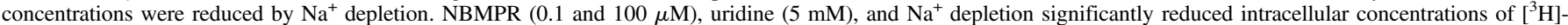

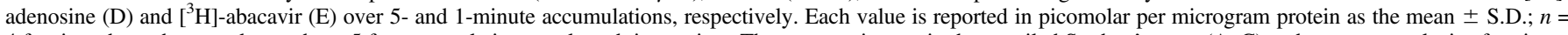

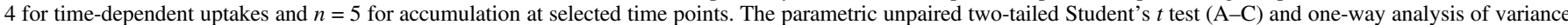

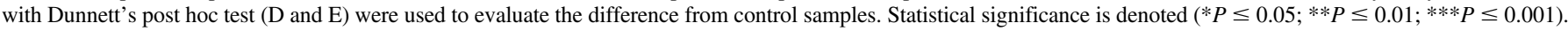


Subsequently, NBMPR $(0.1$ and $100 \mu \mathrm{M})$, uridine $(5 \mathrm{mM})$, and $\mathrm{Na}^{+}$ depletion were shown to reduce $\left[{ }^{3} \mathrm{H}\right]$-adenosine uptake over 5 minutes of incubation by more than $70 \%$ relative to an uninhibited control (Fig. 2D). These results confirmed the activity of ENT1 and CNTs in BeWo cells. All tested inhibitors affected 1-minute accumulation of $\left[{ }^{3} \mathrm{H}\right]$ abacavir in a similar but less-pronounced fashion, reducing its uptake by around $30 \%$ (Fig. 2E), suggesting a contribution of ENT1 and other $\mathrm{Na}^{+}-$ dependent transporters, most likely CNTs, to $\left[{ }^{3} \mathrm{H}\right]$-abacavir membrane transfer.

Ex Vivo Analysis of Nucleoside Transporters' Role in $\left[{ }^{3} \mathbf{H}\right]-$ Abacavir Uptake by Human Fresh Villous Placental Fragments. We performed ex vivo accumulation studies with fresh villous fragments isolated from the human placenta to evaluate the role of ENTs and CNTs in abacavir uptake. We observed that the placental fragments exhibited a time-dependent increase in $\left[{ }^{3} \mathrm{H}\right]$-adenosine $(21.8 \mathrm{nM})$ and $\left[{ }^{3} \mathrm{H}\right]$ thymidine $(6 \mathrm{nM})$ accumulation without any significant effect of $\mathrm{Na}^{+}$ depletion (Fig. 3, A and B). This suggests no or negligible activity of CNTs in the apical membrane of the term placenta. NBMPR $(100 \mu \mathrm{M})$ reduced time-dependent accumulation of both model substrates, confirming ENT activity (Fig. 3, A and B). Over a 5-minute $\left[{ }^{3} \mathrm{H}\right]$-adenosine accumulation period, the effect of treatment with NBMPR at $0.1 \mu \mathrm{M}$ was similar to that for treatment at $100 \mu \mathrm{M}$ (Fig. 3D), indicating that, of the ENTs, ENT1 is a dominant adenosine placental transporter; in contrast, uridine (5 mM) had no significant effect (Fig. 3D).

The accumulation of $\left[{ }^{3} \mathrm{H}\right]$-abacavir was also time-dependent, although it was insensitive to both the presence of NBMPR $(100 \mu \mathrm{M})$ and depletion of $\mathrm{Na}^{+}$(Fig. 3C). Moreover, upon a 5-minute incubation period, none of the tested inhibitors revealed a significant effect on $\left[{ }^{3} \mathrm{H}\right]$ abacavir uptake into fresh villous fragments after 5 minutes of incubation (Fig. 3E).

Investigation of Nucleoside Transporters' Effects on $\left[{ }^{3} \mathrm{H}\right]$ Abacavir Uptake into Human Placental MVM Vesicles. Because of the discrepancies between our in vitro and ex vivo results, we evaluated the role of ENTs and CNTs in $\left[{ }^{3} \mathrm{H}\right]$-abacavir uptake directly in MVM vesicles. $\left[{ }^{3} \mathrm{H}\right]$-Adenosine $(0.145 \mu \mathrm{M}),\left[{ }^{3} \mathrm{H}\right]$-thymidine $(1 \mu \mathrm{M})$, and $\left[{ }^{3} \mathrm{H}\right]$-abacavir $(5 \mu \mathrm{M})$ showed time-dependent accumulation into MVM vesicles (Fig. 4, A-C). As observed in villous fragments, the uptakes were insensitive to $\mathrm{Na}^{+}$depletion, confirming no or negligible functional expression of CNTs in the apical membrane of the term placenta. Addition of NBMPR $(0.1$ or $100 \mu \mathrm{M})$ or uridine $(1 \mathrm{mM})$ caused significant reduction in the 1-minute accumulation of $\left[{ }^{3} \mathrm{H}\right]$ adenosine (Fig. 4D), indicating the functional activity of ENTs in MVM vesicles. A similar inhibition pattern was observed in the case of $\left[{ }^{3} \mathrm{H}\right]$ abacavir (Fig. 4E) over 1-minute uptake. Furthermore, we tested the inhibitory potential of adenosine $(1 \mathrm{mM})$ in $\left[{ }^{3} \mathrm{H}\right]$-abacavir accumulation, revealing an effect comparable to uridine $(1 \mathrm{mM})$. A significant effect of $100 \mu \mathrm{M}$ NBMPR on $\left[{ }^{3} \mathrm{H}\right]$-abacavir uptake into MVM vesicles was also observed over 5- and 10-minute incubations (Fig. 4C).

In Situ Open-Circuit Perfusion of the Rat Term Placenta; Effect of ENTs on Transplacental $\left[{ }^{3} \mathbf{H}\right]$-Abacavir Clearance. Because uptake studies performed in vitro and using MVM vesicles had indicated that ENTs may drive placental $\left[{ }^{3} \mathrm{H}\right]$-abacavir uptake, we investigated the ability of rat Ent(s) to facilitate abacavir transfer across the placental barrier. Treatment with NBMPR $(0.1,100 \mu \mathrm{M})$ or uridine $(5 \mathrm{mM})$
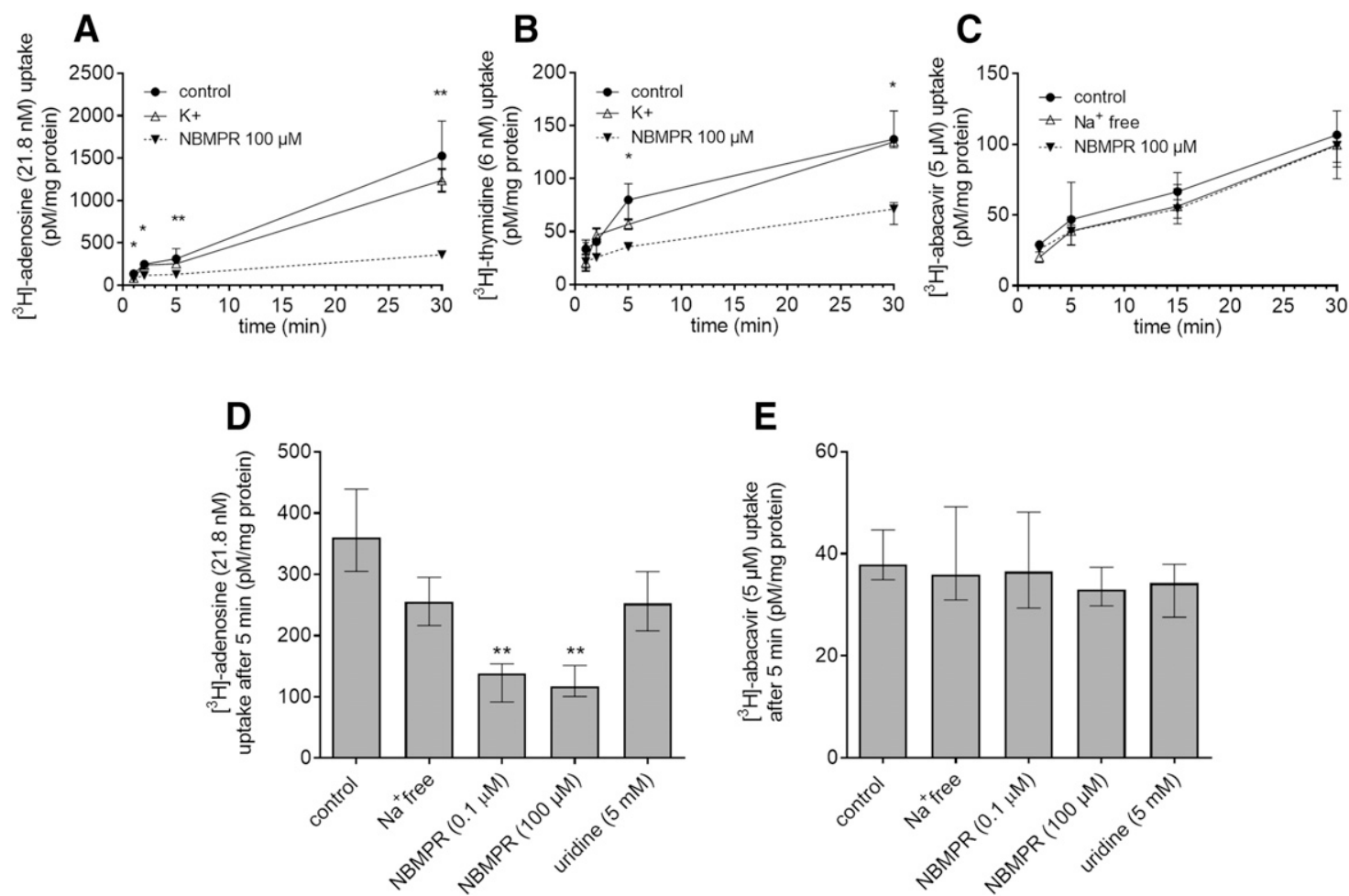

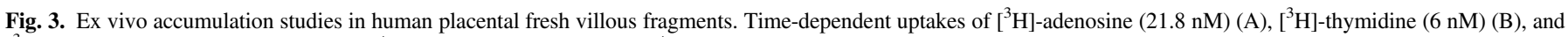

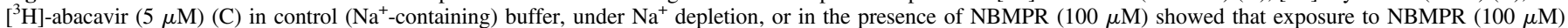

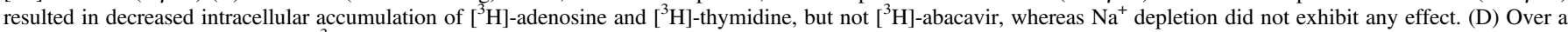

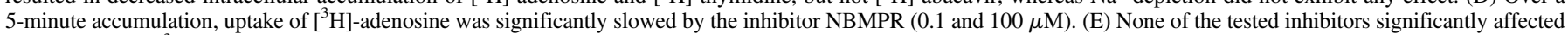

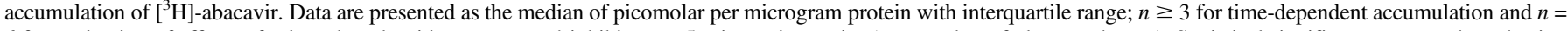

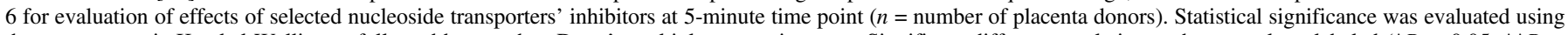

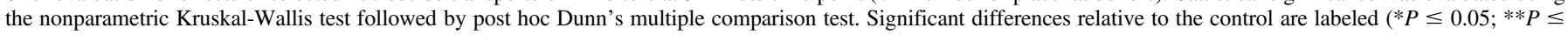
$0.01)$. 

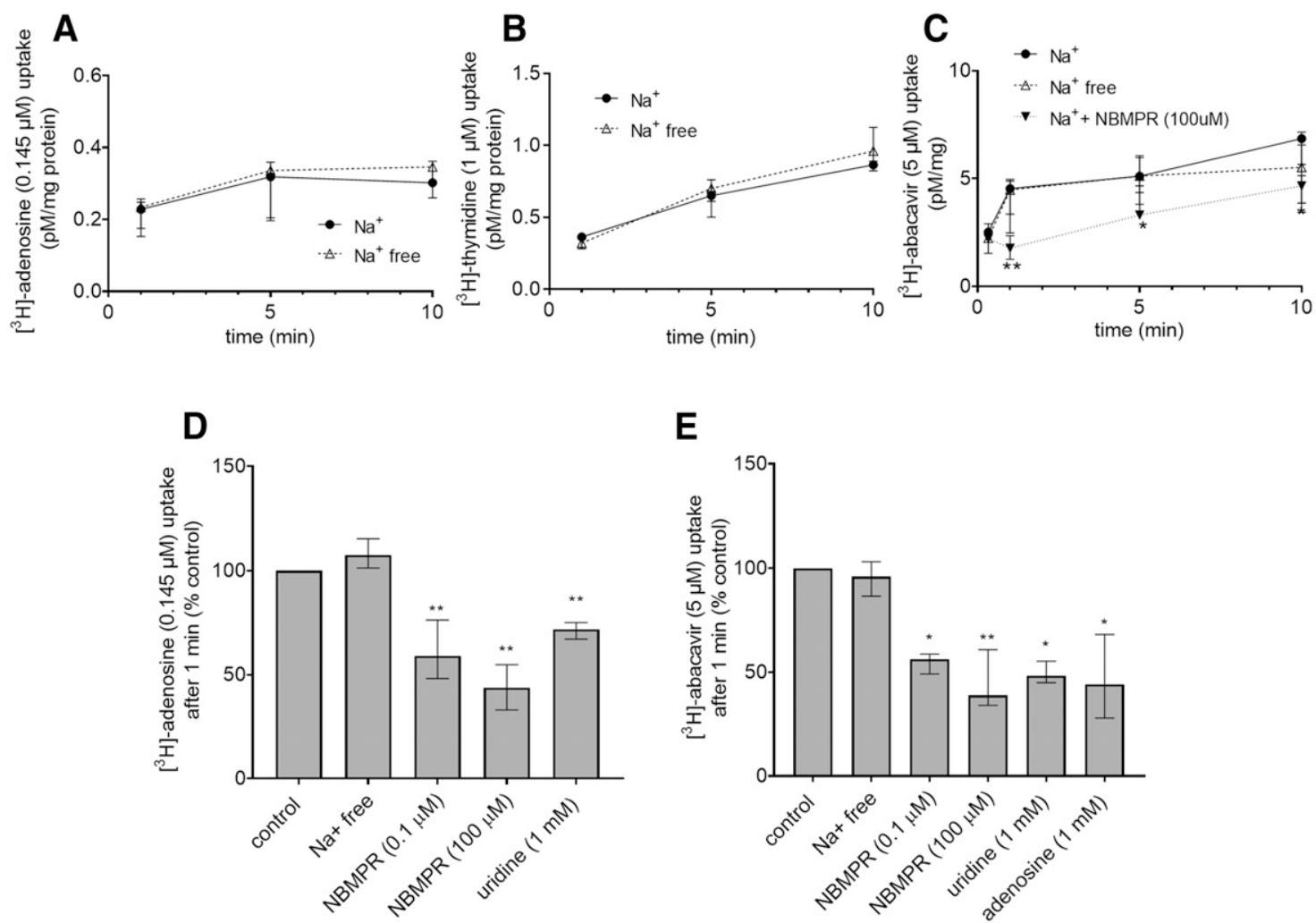

Fig. 4. Ex vivo accumulation studies in human MVM vesicles isolated from human term placentas. Time-dependent uptake studies with $\left[{ }^{3} \mathrm{H}\right]$-adenosine $(0.145 \mu \mathrm{M})(\mathrm{A})$, $\left[{ }^{3} \mathrm{H}\right]$-thymidine $(1 \mu \mathrm{M})(\mathrm{B})$, and $\left[{ }^{3} \mathrm{H}\right]$-abacavir $(5 \mu \mathrm{M})(\mathrm{C})$ in control $\left(\mathrm{Na}^{+}\right.$-containing) buffer, under $\mathrm{Na}^{+}$depletion, or in the presence of $\mathrm{NBMPR}(100 \mu \mathrm{M})$ showed that $\mathrm{Na}^{+}$ depletion did not cause any significant effect on $\left[{ }^{3} \mathrm{H}\right]$-adenosine, $\left[{ }^{3} \mathrm{H}\right]$-thymidine, or $\left[{ }^{3} \mathrm{H}\right]$-abacavir, and NBMPR $(100 \mu \mathrm{M})$ significantly slowed $\left[{ }^{3} \mathrm{H}\right]$-abacavir accumulation. One-minute accumulation of $\left[^{3} \mathrm{H}\right]$-adenosine (D) and $5 \mu \mathrm{M}\left[{ }^{3} \mathrm{H}\right]$-abacavir (E) was significantly decreased in the presence of NBMPR $(0.1$ or $100 \mu \mathrm{M})$ or uridine $(1 \mathrm{mM})$ Additionally, adenosine $(1 \mathrm{mM})$ showed a significant effect on $\left[{ }^{3} \mathrm{H}\right]$-abacavir uptake. The data are presented as the median with interquartile range $(n \geq 3$ for time-dependent uptakes and $n=9$ for 1-minute accumulation studies). Significance was evaluated by multiple nonparametric Wilcoxon matched-pairs signed rank tests; significant differences relative to the control are denoted $(* P \leq 0.05 ; * * P \leq 0.01)$.

caused similar and significant changes in total $\left[{ }^{3} \mathrm{H}\right]$-abacavir transplacental clearance, reducing it by $\approx 50 \%$ in both the $\mathrm{M} \rightarrow \mathrm{F}(\mathrm{Fig} .5 \mathrm{~A})$ and $\mathrm{F} \rightarrow \mathrm{M}$ (Fig. 5B) directions. This strongly suggests that Ent1 does participate in abacavir transport across the rat term placenta into fetal circulation. In all cases, the proportion of placental tissue-bound $\left[{ }^{3} \mathrm{H}\right]$ abacavir was below $1 \%$ (data not shown).

In Situ Closed-Circuit Perfusion of the Rat Term Placenta; Effect of NBMPR $(0.1 \mu M)$ on Fetal-To-Maternal Transport of $\left[{ }^{3} \mathbf{H}\right]$-Abacavir at Equilibrium. To further study transplacental abacavir transport, both sides of the placenta were perfused with the concentration of $\left[{ }^{3} \mathrm{H}\right]$-abacavir (300 nM) used in the closed-circuit experimental setup, and we analyzed the time course of $\left[{ }^{3} \mathrm{H}\right]$-abacavir fetal concentration (Fig. 6A). The fetal-to-maternal concentration ratio after 60 minutes of recirculation was subsequently quantified (Fig. 6B). NBMPR at a concentration of $0.1 \mu \mathrm{M}$ significantly slowed $\mathrm{F} \rightarrow \mathrm{M}$ transport of $\left[{ }^{3} \mathrm{H}\right]$ abacavir (Fig. 6A), increasing the fetal-to-maternal concentration ratio (Fig. 6B). This suggests that NBMPR $(0.1 \mu \mathrm{M})$ might inhibit Ent1- or Ent1-like uptake of $\left[{ }^{3} \mathrm{H}\right]$-abacavir on the basal membrane of the syncytiotrophoblast in the rat term placenta, thus abolishing $\mathrm{F} \rightarrow \mathrm{M}$ transfer of $\left[{ }^{3} \mathrm{H}\right]$-abacavir against the concentration gradient in rats.

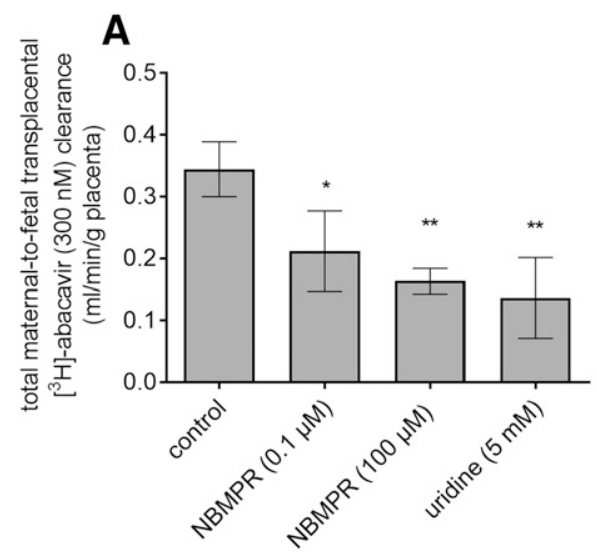

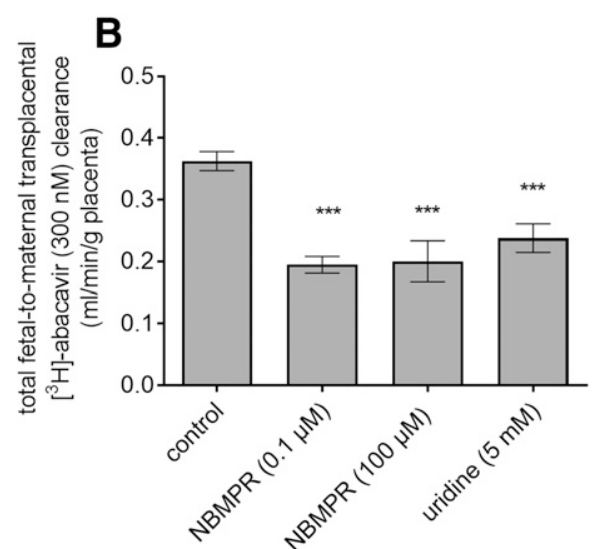

Fig. 5. Open-circuit perfusion experiments; effect of ENTs on transplacental clearance of $\left[{ }^{3} \mathrm{H}\right]$-abacavir $(0.06 \mu \mathrm{Ci} / \mathrm{ml}, 300 \mathrm{nM})$ in the $\mathrm{M} \rightarrow \mathrm{F}$ (A) and $\mathrm{F} \rightarrow \mathrm{M}$ (B) directions. Both NBMPR (at concentrations of 0.1 or $100 \mu \mathrm{M}$ ) and uridine $(5 \mathrm{mM})$ significantly reduced transplacental $\left[{ }^{3} \mathrm{H}\right]$-abacavir clearance in both directions, implying Ent1 facilitates abacavir passage across the placenta. The proportion of $\left[{ }^{3} \mathrm{H}\right]$-abacavir bound to placental tissues was below $1 \%$ in all cases (data not shown). Data are presented as the mean \pm S.D., $n=4$. Significance was evaluated by one-way analysis of variance followed by post hoc Dunnett's multiple comparison test; statistically significant differences from the control are denoted (*P $\leq 0.05 ; * * P \leq 0.01 ; * * * P \leq 0.001)$. 


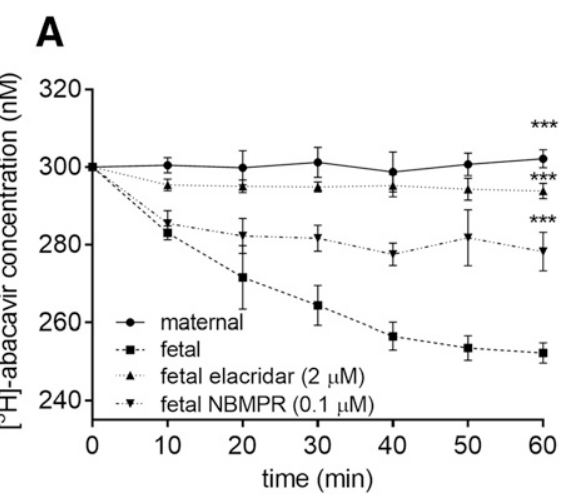

B

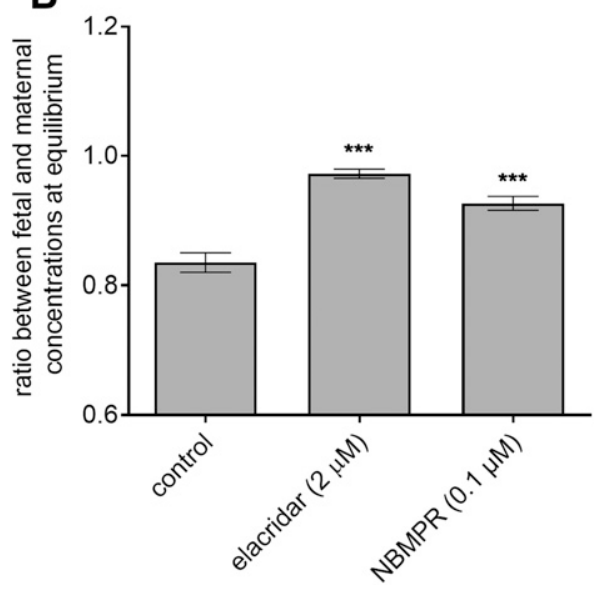

Fig. 6. Closed-circuit perfusion experiments; effect of NBMPR $(0.1 \mu \mathrm{M})$ on fetal-tomaternal transport of $\left[{ }^{3} \mathrm{H}\right]$-abacavir $(300 \mathrm{nM})$ at equilibrium. We analyzed the time course of the fetal $\left[{ }^{3} \mathrm{H}\right]$-abacavir concentration (A) and used the fetal-to-maternal concentration ratio to quantify the drug's transport after 60 minutes of recirculation (B). Adding NBMPR $(0.1 \mu \mathrm{M})$ to both compartments significantly slowed the overall $\left[{ }^{3} \mathrm{H}\right]$-abacavir transfer against the concentration gradient in the maternal-to-fetal direction, leading to a significant increase in the fetal-to-maternal concentration ratio after 60 minutes. Results are presented as the mean \pm S.D. Significance was evaluated by one-way analysis of variance followed by post hoc Dunnett's multiple comparison test; significant differences relative to the fetal concentration (A) or results for control animals (B) are denoted $(* * * P \leq 0.001)$ and are based on $n=$ 3 measurements in all cases.
Quantitative Reverse-Transcription PCR Analysis of $h S L C 29 A 1 / r S l c 29 a 1$ and $h S L C 29 A 2 / r S l c 29 a 2$ Expression in Firstand Third-Trimester Human Placentas, Rat Term Placentas, and BeWo Cells. To date, mRNA expression of placental SLC29A/Slc29a transporters has been quantitatively assessed only in term placentas of rats (Leazer and Klaassen, 2003; Nishimura et al., 2012), not in BeWo cells or human first-/third-trimester placentas. The normalized expression of hSLC29A1 in first- and third-trimester human placentas was significantly greater than that of $h S L C 29 A 2$ (by a factor of around 30); the level of hSLC29A2 mRNA was below the limit of detection in two samples of both first- and third-trimester placentas (Fig. 7A). For both hSLC29A1 and hSLC29A2, the level of mRNA in the first-trimester placenta was similar to that in the third. However, both genes exhibited considerable interindividual variability; in the case of $h S L C 29 A 2$, the observed levels varied over two orders of magnitude (Fig. 7A). The expression of $r S l c 29 a 1$ in the rat term placentas was 15-fold stronger than that of $r S l c 29 a 2$ (Fig. 7B), further confirming the published data, and the expression of $h S L C 29 A 1$ in BeWo cells was 40-fold higher than that of hSLC29A2 (Fig. 7C).

\section{Discussion}

To fully assess the safety profile of pharmacotherapy in pregnant women, it is important to understand factors potentially affecting transplacental pharmacokinetics (Brownbill et al., 2016). As abacavir is a nucleoside analog, our study is the first attempt to investigate the role of nucleoside transporters in its transplacental transfer.

We first confirmed the presence of SLC29A1 and SLC29A2 mRNA in the BeWo cell line and human/rat term placentas (Fig. 1). Subsequently, we used the accumulation method in BeWo cells, a well established in vitro model for studying drug interactions with placental ABCB1 and ABCG2 transporters (Utoguchi et al., 2000; Ceckova et al., 2006) as well as with SLC transporters (Boumah et al., 1992; Mani et al., 1998; Yamamoto et al., 2007; Nabekura et al., 2015; Karbanova et al., 2017; Ma et al., 2017). The presence of functional ENTs in BeWo cells has previously been confirmed by binding assays with NBMPR and by observing the effect of NBMPR on the accumulation of thymidine (Boumah et al., 1992; Mani et al., 1998; Karbanova et al., 2017). Recently, we have shown that our clone of BeWo expresses SLC28A2 and lower levels of SLC28A3 mRNA (Jiraskova et al., 2018). Here, we observed the effect of $\mathrm{Na}^{+}$depletion on $\left[{ }^{3} \mathrm{H}\right]$-adenosine $(\mathrm{CNT} 2$ and CNT3 substrate) but not $\left[{ }^{3} \mathrm{H}\right]$-thymidine (CNT1 and CNT3 substrate) (Molina-Arcas et al., 2009) (Fig. 2, A and B). Therefore, we suggest the functional expression of only CNT2 in BeWo cells. As $\left[{ }^{3} \mathrm{H}\right]$-abacavir uptake into BeWo cells was sensitive to $\mathrm{Na}^{+}$depletion (Fig. 2, C and E), we concluded that CNT2 may contribute to this phenomenon. Subsequently, we used $\left[{ }^{3} \mathrm{H}\right]$-adenosine to study the effects of particular
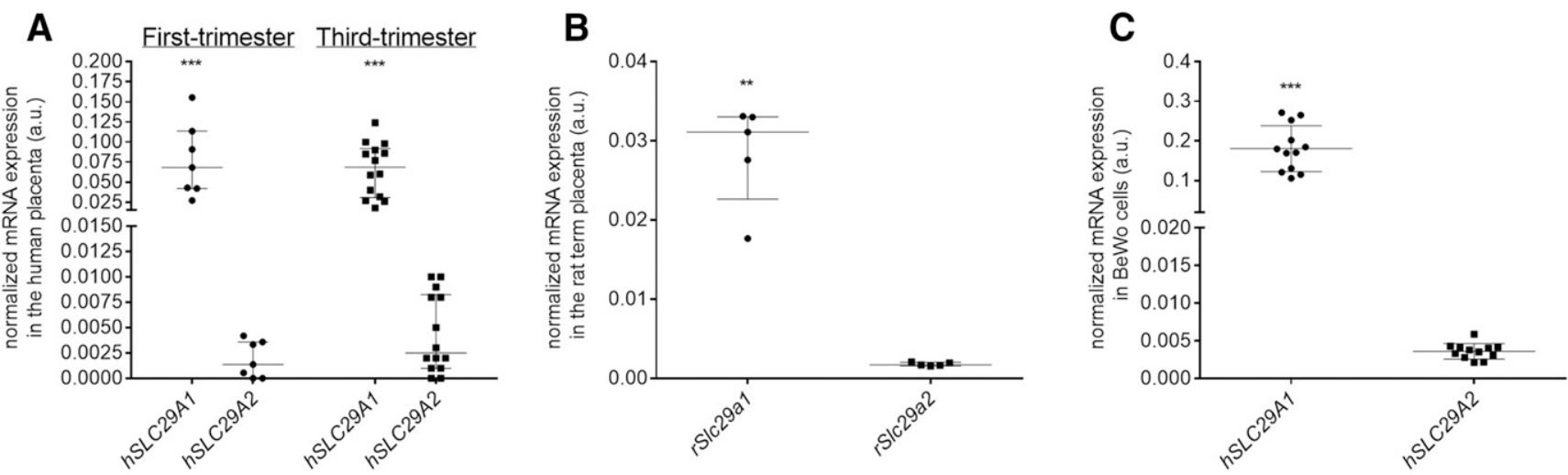

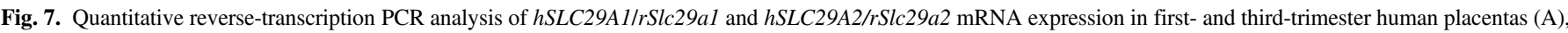

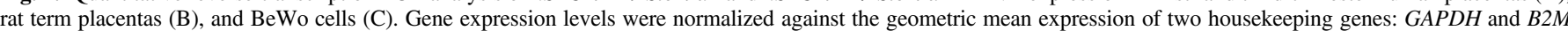

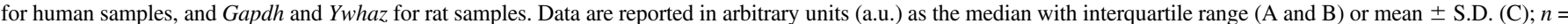

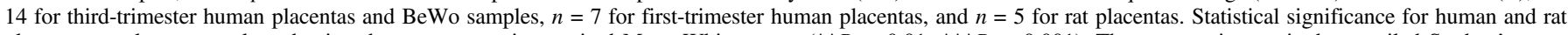

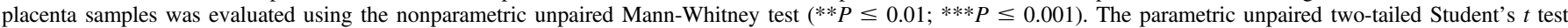
$(* * * P \leq 0.001)$ was used to evaluate significance for BeWo cells. 
inhibitors because its structure resembles abacavir more closely than does that of thymidine. NBMPR at both tested concentrations $(0.1$ and $100 \mu \mathrm{M})$ and uridine $(5 \mathrm{mM})$ induced comparable reductions in $\left[{ }^{3} \mathrm{H}\right]$ adenosine uptake into BeWo cells (Fig. 2D), indicating that the observed effect was solely due to ENT1. Time-dependent uptake and a similar pattern of NBMPR effects were observed with $\left[{ }^{3} \mathrm{H}\right]$-abacavir, suggesting that abacavir uptake into BeWo cells is driven by ENT1 without any detectable contribution of ENT2 (Fig. 2, C and E).

To further study the nucleoside transporter-mediated placental uptake of abacavir, we investigated its accumulation into fresh villous fragments that have been previously used to study human placental amino acid transport (Greenwood and Sibley, 2006) and the interactions of abacavir with ABCB1 and ABCG2 (Neumanova et al., 2015) and zidovudine/ emtricitabine with ENTs (Karbanova et al., 2017). We validated this experimental model using $\left[{ }^{3} \mathrm{H}\right]$-adenosine and $\left[{ }^{3} \mathrm{H}\right]$-thymidine, observing time-dependent uptakes. Significant sensitivity to treatment with $100 \mu \mathrm{M}$ NBMPR confirmed functional ENT expression; however, we did not see any effect of $\mathrm{Na}^{+}$depletion (Fig. 3, A and B). Five-minute experiments with $\left[{ }^{3} \mathrm{H}\right]$-adenosine in the presence of NBMPR $(0.1 \mu \mathrm{M})$ reinforced the conclusion that placental $\left[{ }^{3} \mathrm{H}\right]$-adenosine uptake is substantially driven by ENT1 (Fig. 3D). The overall influence of the tested inhibitors on $\left[{ }^{3} \mathrm{H}\right]-$ abacavir accumulation was negligible (Fig. 3E). Lack of a significant role of ENTs on $\left[{ }^{3} \mathrm{H}\right]$-abacavir uptake in villous fragments might be caused by a lower affinity of abacavir to ENT1 compared with adenosine and/or higher lipophilicity (abacavir $\log \mathrm{P}=1.2$ vs. adenosine $\log \mathrm{P}=-1.05$ ), potentially leading to increased uptake into other cell types (e.g., macrophages, endothelium, and/or smooth muscle cells) (Greenwood and Sibley, 2006).
Given the discrepancy between results in villous fragments and BeWo cells, we performed accumulation studies directly in human placentaderived MVM vesicles (Glazier and Sibley, 2006). This method has previously been used to investigate the role of nucleoside transporters in placental nucleoside uptake (Barros et al., 1991; Errasti-Murugarren et al., 2011). We observed time-dependent $\left[{ }^{3} \mathrm{H}\right]$-adenosine, $\left[{ }^{3} \mathrm{H}\right]$ thymidine, and $\left[{ }^{3} \mathrm{H}\right]$-abacavir uptakes, and by comparing the inhibitory potencies of two NBMPR concentrations $(0.1$ and $100 \mu \mathrm{M})$, we confirmed ENT1-mediated uptake of $\left[{ }^{3} \mathrm{H}\right]$-adenosine and $\left[{ }^{3} \mathrm{H}\right]$ abacavir by the MVM vesicles (Fig. 4). On the other hand, the uptakes were insensitive to $\mathrm{Na}^{+}$depletion (Fig. 4), which is in line with previous findings drawn from studies in human (Barros et al., 1991) and rat MVM vesicles (Nishimura et al., 2012) and our observations in villous fragments (Fig. 3).

The different effects of $\mathrm{Na}^{+}$depletion in BeWo cells and ex vivo human placental models can be explained by a three-orders-ofmagnitude higher expression of SLC28A2 (coding for CNT2) in BeWo cells when compared with the human placenta (Jiraskova et al., 2018). Moreover, the lack of CNT effect seems to be in accordance with the observation by Govindarajan et al. (2007), who did not detect any protein expression of CNTs in the trophoblast layer of the term placenta. Because the levels of CNTs increase over the course of gestation (Jiraskova et al., 2018), we do not hypothesize that CNTs are involved in maternal-placental transfer in earlier phases of gestation either.

In the next step, we used an in situ model based on dually perfused rat placentas in open- and closed-circuit setups to evaluate the overall contribution of Ent(s) to transplacental abacavir kinetics at the organ level. Dual perfusion of the rat term placenta is an established and well
A

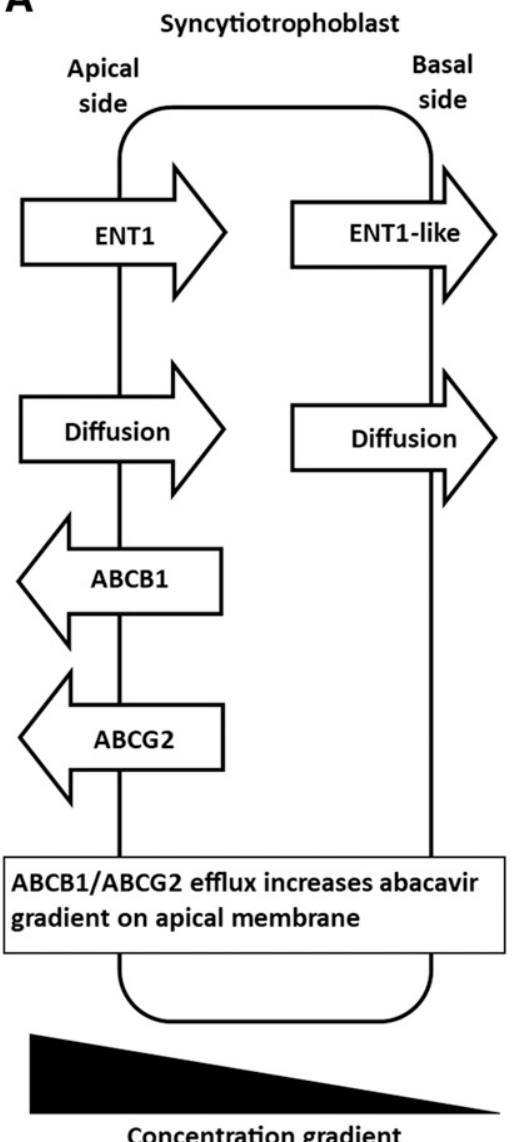

B

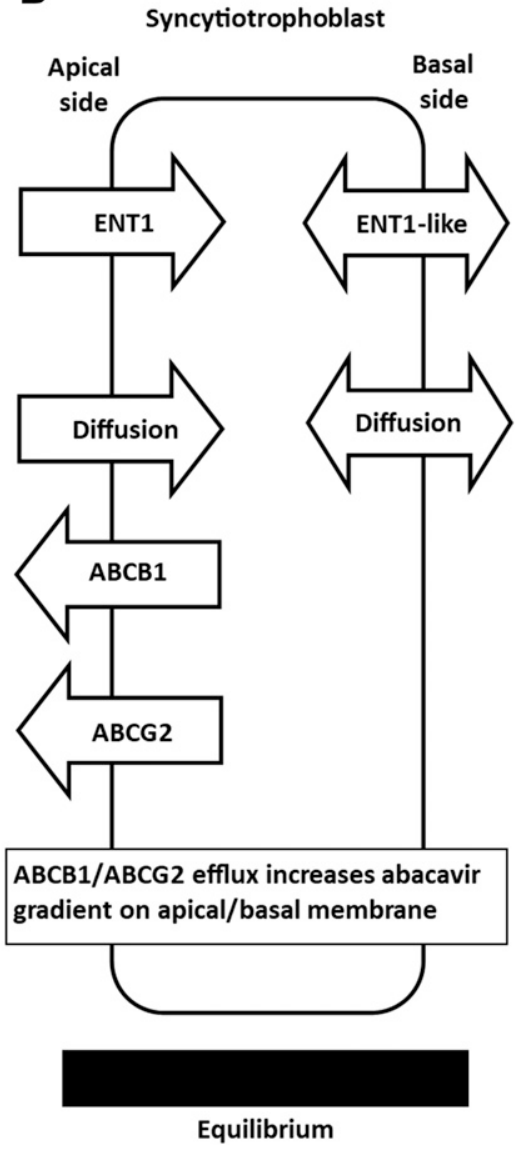

Fig. 8. Hypothesized role of ENT1, ENT1-like, ABCB1, ABCG2, and passive diffusion in the transfer of abacavir across the syncytiotrophoblast when the maternal abacavir concentration is higher than the fetal concentration (A) and at equilibrium (B). In the former case, ENT1 and passive diffusion transfer abacavir unidirectionally from the maternal to the fetal circulation, outweighing the efflux activity of $\mathrm{ABCB} 1$ and $\mathrm{ABCG} 2$. At equilibrium, $\mathrm{ABCB} 1 / \mathrm{ABCG} 2$ activity probably creates transient concentration gradients on both poles of the syncytiotrophoblast that may drive passive abacavir uptake (via passive diffusion and diffusion facilitated by ENT1 on the apical membrane and ENT1like on the basal membrane) back into the syncytiotrophoblast. However, when the intracellular concentration exceeds the fetal concentration, we assume that ENT1-like- and passive diffusionmediated transport act in opposite directions. We thus speculate that passive transport of abacavir is unidirectional on the apical membrane but may be bidirectional on the basal membrane. 
justified method that has been used to investigate the interactions of placental ABC and SLC transporters with various drugs, including abacavir (Ahmadimoghaddam et al., 2012; Ahmadimoghaddam and Staud, 2013; Neumanova et al., 2014, 2015, 2016; Ceckova et al., 2016). ENTs in the placenta of Wistar rats have been functionally characterized by analyzing adenosine uptake from the maternal blood circulation into the feto-placental unit and into MVM vesicles prepared from the rat placenta (Nishimura et al., 2012). In the open-circuit setup, all tested inhibitors substantially reduced the total clearance of $\left[{ }^{3} \mathrm{H}\right]$-abacavir in the $\mathrm{M} \rightarrow \mathrm{F}$ and $\mathrm{F} \rightarrow \mathrm{M}$ directions in a comparable manner (Fig. 5). These results suggest that ENT1 is an important transporter for more than just placental uptake, and that it also mediates the transport of abacavir into fetal circulation. The effect of $\mathrm{Na}^{+}$depletion could not be investigated in this model, as this condition deleteriously affected the rat term placenta, causing edema and high pressure during the experiment. In closedcircuit dual-perfusion experiments, NBMPR $(0.1 \mu \mathrm{M})$ significantly reduced fetal-to-maternal transport of $\left[{ }^{3} \mathrm{H}\right]$-abacavir (Fig. 6). This was surprising because inhibiting apically localized Ent1 should have the opposite effect, further reducing the abacavir concentration in fetal circulation. However, our observation seems to be consistent with previous reports describing Ent1-like activity on the basal membrane of the syncytiotrophoblast (Barros et al., 1995; Govindarajan et al., 2007; Errasti-Murugarren et al., 2011). When considering our previously published data (Neumanova et al., 2015) and the data presented here, we hypothesize cross-talk among placental ABCB1, ABCG2, and ENT1 that might differ at concentration equilibrium and when the maternal abacavir concentration is higher than the fetal concentration (Fig. 8).

In the next step, we quantified the mRNA expression in the placental models/tissues showing that $h S L C 29 A 1$ is the dominantly transcribed ENT in BeWo cells and in the first- and third-trimester human placenta (Fig. 7), and we confirmed a previously reported expression profile of rSlc29a expression in rat term placenta (Leazer and Klaassen, 2003; Nishimura et al., 2012). Low hSLC29A2 placental expression may thus hamper the capability of our experimental models to detect abacavir interactions with ENT2. In contrast to findings for other placental transporters (e.g., ABCB1, ABCG2, and CNTs) (Gil et al., 2005; Meyer zu Schwabedissen et al., 2006; Jiraskova et al., 2018), the expression of $h S L C 29 A 1$ and $h S L C 29 A 2$ did not change in the course of gestation (Fig. 7A). On the other hand, considerable interindividual variability was observed for both genes (Fig. 7A). Because the mRNA seems to correlate with ENT1 function, as evidenced in pharmacoresistance studies (Giovannetti et al., 2006; Marcé et al., 2006; Tsujie et al., 2007; Eto et al., 2013), we hypothesize that the observed placental mRNA variability might be reflected in protein/function level. Therefore, it may represent a potential reason for differences in reported cord-to-maternal blood concentration ratios (Chappuy et al., 2004; Best et al., 2006; Fauchet et al., 2014).

This study provides the first evidence that ENT1 is the dominant placental ENT isoform showing significant uptake of nucleosides, whereas ENT2 and CNTs do not exhibit any activity on the apical side of the syncytiotrophoblast in the term placenta. We also showed for the first time that the expression of SLC29A1 and SLC29A2 mRNA is comparable in the first- and third-trimester placenta, although there is substantial interindividual variability in the expression of both genes. Drug-drug interactions (e.g., with suggested substrates of ENT ribavirin) and role of interindividual variability in placental ENT1 expression in drug disposition into fetal circulation of ENT substrates should be further investigated to guarantee safe and effective abacavir-based combination therapies in pregnancy.

\section{Acknowledgments}

We thank Dr. Marian Kacerovsky (Department of Obstetrics and Gynecology, University Hospital in Hradec Kralove) for providing us with human placentas, and Martina Hudeckova for help with the human placenta collection and sampling. We also thank Dana Souckova and Renata Exnarova for their skillful assistance with the perfusion experiments.

\section{Authorship Contributions}

Participated in research design: Cerveny, Ptackova, Ceckova, Karahoda, Greenwood, Glazier, Staud.

Conducted experiments: Cerveny, Ptackova, Ceckova, Karahoda, Karbanova, Jiraskova.

Performed data analysis: Cerveny, Ptackova, Ceckova, Karahoda, Greenwood, Glazier.

Wrote or contributed to the writing of the manuscript: Cerveny, Ptackova, Ceckova, Karahoda, Greenwood, Glazier, Staud.

\section{References}

Acevedo CG, Rojas S, Ramirez M, and Bravo I (1995) Transport and metabolism of adenosine in the perfused human placenta. Placenta 16:611-622.

Ahmadimoghaddam D, Hofman J, Zemankova L, Nachtigal P, Dolezelova E, Cerveny L, Ceckova M, Micuda S, and Staud F (2012) Synchronized activity of organic cation transporter 3 (Oct3/ Slc22a3) and multidrug and toxin extrusion 1 (Mate1/Slc47a1) transporter in transplacental passage of MPP+ in rat. Toxicol Sci 128:471-481.

Ahmadimoghaddam D and Staud F (2013) Transfer of metformin across the rat placenta is mediated by organic cation transporter 3 (OCT3/SLC22A3) and multidrug and toxin extrusion 1 (MATE1/SLC47A1) protein. Reprod Toxicol 39:17-22.

Ahmadimoghaddam D, Zemankova L, Nachtigal P, Dolezelova E, Neumanova Z, Cerveny L, Ceckova M, Kacerovský M, Micuda S, and Staud F (2013) Organic cation transporter 3 (OCT3/ SLC22A3) and multidrug and toxin extrusion 1 (MATE1/SLC47A1) transporter in the placenta and fetal tissues: expression profile and fetus protective role at different stages of gestation. Biol Reprod 88:55.

Atkinson DE, Sibley CP, Fairbairn LJ, and Greenwood SL (2006) MDR1 P-gp expression and activity in intact human placental tissue; upregulation by retroviral transduction. Placenta 27 707-714.

Barros LF, Bustamante JC, Yudilevich DL, and Jarvis SM (1991) Adenosine transport and nitrobenzylthioinosine binding in human placental membrane vesicles from brush-border and basal sides of the trophoblast. J Membr Biol 119:151-161.

Barros LF, Yudilevich DL, Jarvis SM, Beaumont N, Young JD, and Baldwin SA (1995) Immunolocalisation of nucleoside transporters in human placental trophoblast and endothelial cells: evidence for multiple transporter isoforms. Pflugers Arch 429:394-399.

Best BM, Mirochnick M, Capparelli EV, Stek A, Burchett SK, Holland DT, Read JS, Smith E, Hu C, Spector SA, et al.; PACTG P1026s Study Team (2006) Impact of pregnancy on abacavir pharmacokinetics. AIDS 20:553-560.

Boumah CE, Hogue DL, and Cass CE (1992) Expression of high levels of nitrobenzylthioinosinesensitive nucleoside transport in cultured human choriocarcinoma (BeWo) cells. Biochem J 288: 987-996.

Brownbill P, Chernyavsky I, Bottalico B, Desoye G, Hansson S, Kenna G, Knudsen LE, Markert UR, Powles-Glover N, Schneider H, et al. (2016) An international network (PlaNet) to evaluate a human placental testing platform for chemicals safety testing in pregnancy. Reprod Toxicol 64: 191-202.

Ceckova M, Libra A, Pavek P, Nachtigal P, Brabec M, Fuchs R, and Staud F (2006) Expression and functional activity of breast cancer resistance protein (BCRP, ABCG2) transporter in the human choriocarcinoma cell line BeWo. Clin Exp Pharmacol Physiol 33:58-65.

Ceckova M, Reznicek J, Ptackova Z, Cerveny L, Müller F, Kacerovsky M, Fromm MF, Glazier JD, and Staud F (2016) Role of ABC and solute carrier transporters in the placental transport of lamivudine. Antimicrob Agents Chemother 60:5563-5572.

Cerveny L, Neumanova Z, Karbanova S, Havlova I, and Staud F (2016) Long-term administration of tenofovir or emtricitabine to pregnant rats; effect on Abcb1a, Abcblb and Abcg2 expression in the placenta and in maternal and fetal organs. J Pharm Pharmacol 68:84-92.

Cerveny L, Ptackova Z, Durisova M, and Staud F (2018) Interactions of protease inhibitors atazanavir and ritonavir with $\mathrm{ABCB} 1, \mathrm{ABCG} 2$, and $\mathrm{ABCC} 2$ transporters: effect on transplacental disposition in rats. Reprod Toxicol 79:57-65.

Chappuy H, Tréluyer JM, Jullien V, Dimet J, Rey E, Fouché M, Firtion G, Pons G, and Mandelbrot L (2004) Maternal-fetal transfer and amniotic fluid accumulation of nucleoside analogue reverse transcriptase inhibitors in human immunodeficiency virus-infected pregnant women. Antimicrob Agents Chemother 48:4332-4336.

Chishu T, Sai Y, Nishimura T, Sato K, Kose N, and Nakashima E (2008) Potential of various drugs to inhibit nucleoside uptake in rat syncytiotrophoblast cell line, TR-TBT 18d-1. Placenta 29: $461-467$.

Committee for the Update of the Guide for the Care and Use of Laboratory Animals (2011) Guide for the Care and Use of Laboratory Animals Eighth Edition. The National Academies Press, Washington D.C., ISBN 978-0-309-15401-7.

Dancis J, Lee J, Mendoza S, and Liebes L (1993) Nucleoside transport by perfused human placenta. Placenta 14:547-554.

Errasti-Murugarren E, Díaz P, Godoy V, Riquelme G, and Pastor-Anglada M (2011) Expression and distribution of nucleoside transporter proteins in the human syncytiotrophoblast. Mol Pharmacol 80:809-817.

Eto K, Kawakami H, Kuwatani M, Kudo T, Abe Y, Kawahata S, Takasawa A, Fukuoka M, Matsuno Y, Asaka M, et al. (2013) Human equilibrative nucleoside transporter 1 and Notch3 can predict gemcitabine effects in patients with unresectable pancreatic cancer. Br J Cancer 108:1488-1494

Fauchet F, Treluyer JM, Préta LH, Valade E, Pannier E, Urien S, and Hirt D (2014) Population pharmacokinetics of abacavir in pregnant women. Antimicrob Agents Chemother 58:6287-6289. Gil S, Saura R, Forestier F, and Farinotti R (2005) P-glycoprotein expression of the human placenta during pregnancy. Placenta 26:268-270.

Giovannetti E, Del Tacca M, Mey V, Funel N, Nannizzi S, Ricci S, Orlandini C, Boggi U, Campani D, Del Chiaro M, et al. (2006) Transcription analysis of human equilibrative nucleoside 
transporter-1 predicts survival in pancreas cancer patients treated with gemcitabine. Cancer Res 66:3928-3935.

Giri N, Shaik N, Pan G, Terasaki T, Mukai C, Kitagaki S, Miyakoshi N, and Elmquist WF (2008) Investigation of the role of breast cancer resistance protein (Bcrp/Abcg2) on pharmacokinetics and central nervous system penetration of abacavir and zidovudine in the mouse. Drug Metab Dispos 36:1476-1484.

Glazier JD, Jones CJ, and Sibley CP (1988) Purification and Na+ uptake by human placental microvillus membrane vesicles prepared by three different methods. Biochim Biophys Acta $\mathbf{9 4 5}$ : 127-134.

Glazier JD and Sibley CP (2006) In vitro methods for studying human placental amino acid transport: placental plasma membrane vesicles. Methods Mol Med 122:241-252.

Godfrey KM, Matthews N, Glazier J, Jackson A, Wilman C, and Sibley CP (1998) Neutral amino acid uptake by the microvillous plasma membrane of the human placenta is inversely related to fetal size at birth in normal pregnancy. J Clin Endocrinol Metab 83:3320-3326.

Govindarajan R, Bakken AH, Hudkins KL, Lai Y, Casado FJ, Pastor-Anglada M, Tse CM, Hayashi J, and Unadkat JD (2007) In situ hybridization and immunolocalization of concentrative and equilibrative nucleoside transporters in the human intestine, liver, kidneys, and placenta. Am J Physiol Regul Integr Comp Physiol 293:R1809-R1822.

Greenwood SL and Sibley CP (2006) In vitro methods for studying human placental amino acid transport placental villous fragments. Methods Mol Med 122:253-264.

Griffiths M, Yao SY, Abidi F, Phillips SE, Cass CE, Young JD, and Baldwin SA (1997) Molecula cloning and characterization of a nitrobenzylthioinosine-insensitive (ei) equilibrative nucleoside transporter from human placenta. Biochem J 328:739-743.

Harrington B, Glazier J, D'Souza S, and Sibley C (1999) System A amino acid transporter activity in human placental microvillous membrane vesicles in relation to various anthropometric measurements in appropriate and small for gestational age babies. Pediatr Res 45:810-814.

Hong M, Schlichter L, and Bendayan R (2000) A $\mathrm{Na}(+)$-dependent nucleoside transporter in microglia. J Pharmacol Exp Ther 292:366-374.

Jiraskova L, Cerveny L, Karbanova S, Ptackova Z, and Staud F (2018) Expression of concentrative nucleoside transporters (SLC28A) in the human placenta: effects of gestation age and prototype differentiation-affecting agents. Mol Pharm 15:2732-2741.

Karbanova S, Cerveny L, Ceckova M, Ptackova Z, Jiraskova L, Greenwood S, and Staud F (2017) Role of nucleoside transporters in transplacental pharmacokinetics of nucleoside reverse transcriptase inhibitors zidovudine and emtricitabine. Placenta 60:86-92.

Kis O, Robillard K, Chan GN, and Bendayan R (2010) The complexities of antiretroviral drug-drug interactions: role of ABC and SLC transporters. Trends Pharmacol Sci 31:22-35.

Leazer TM and Klaassen CD (2003) The presence of xenobiotic transporters in rat placenta. Drug Metab Dispos 31:153-167.

Li RW, Yang C, Chan SW, Hoi MP, Lee SM, Kwan YW, and Leung GP (2015) Relaxation effect of abacavir on rat basilar arteries. PLoS One 10:e0123043.

Ma Z, Yang X, Jiang T, Bai M, Zheng C, Zeng S, Sun D, and Jiang H (2017) Multiple SLC and ABC transporters contribute to the placental transfer of entecavir. Drug Metab Dispos 45: 269-278.

Mahendran D, Byrne S, Donnai P, D’Souza SW, Glazier JD, Jones CJ, and Sibley CP (1994) Na+ transport, $\mathrm{H}+$ concentration gradient dissipation, and system A amino acid transporter activity in purified microvillous plasma membrane isolated from first-trimester human placenta: comparison with the term microvillous membrane. Am J Obstet Gynecol 171:1534-1540.

Mani RS, Hammond JR, Marjan JM, Graham KA, Young JD, Baldwin SA, and Cass CE (1998) Demonstration of equilibrative nucleoside transporters (hENT1 and hENT2) in nuclear envelopes of cultured human choriocarcinoma (BeWo) cells by functional reconstitution in proteoliposomes. J Biol Chem 273:30818-30825.

Mao Q (2008) BCRP/ABCG2 in the placenta: expression, function and regulation. Pharm Res 25: $1244-1255$.

Marcé S, Molina-Arcas M, Villamor N, Casado FJ, Campo E, Pastor-Anglada M, and Colomer D (2006) Expression of human equilibrative nucleoside transporter 1 (hENT1) and its correlation with gemcitabine uptake and cytotoxicity in mantle cell lymphoma. Haematologica 91:895-902.

Meyer zu Schwabedissen HE, Grube M, Dreisbach A, Jedlitschky G, Meissner K, Linnemann K, Fusch C, Ritter CA, Völker U, and Kroemer HK (2006) Epidermal growth factor-mediated activation of the map kinase cascade results in altered expression and function of ABCG2 (BCRP). Drug Metab Dispos 34:524-533.

Molina-Arcas M, Casado FJ, and Pastor-Anglada M (2009) Nucleoside transporter proteins. Curr Vasc Pharmacol 7:426-434.

Nabekura T, Kawasaki T, Kamiya Y, and Uwai Y (2015) Effects of antiviral drugs on organic anion transport in human placental BeWo cells. Antimicrob Agents Chemother 59:7666-7670.

Neumanova Z, Cerveny L, Ceckova M, and Staud F (2014) Interactions of tenofovir and tenofovi disoproxil fumarate with drug efflux transporters $\mathrm{ABCB} 1, \mathrm{ABCG} 2$, and $\mathrm{ABCC} 2$; role in transport across the placenta. AIDS 28:9-17.

Neumanova Z, Cerveny L, Ceckova M, and Staud F (2016) Role of ABCB1, ABCG2, ABCC2 and ABCC5 transporters in placental passage of zidovudine. Biopharm Drug Dispos 37:28-38.

Neumanova Z, Cerveny L, Greenwood SL, Ceckova M, and Staud F (2015) Effect of drug efflux transporters on placental transport of antiretroviral agent abacavir. Reprod Toxicol 57:176-182. Nishimura T, Chishu T, Tomi M, Nakamura R, Sato K, Kose N, Sai Y, and Nakashima E (2012) Mechanism of nucleoside uptake in rat placenta and induction of placental CNT2 in experimental diabetes. Drug Metab Pharmacokinet 27:439-446.

Nishimura T, Tanaka J, Tomi M, Seki Y, Kose N, Sai Y, and Nakashima E (2011) Enhancement of zidovudine transfer to molt-4 cells, a human t-cell model, by dehydroepiandrosterone sulfate. $J$ Pharm Sci 100:3959-3967.

Osses N, Pearson JD, Yudilevich DL, and Jarvis SM (1996) Hypoxanthine enters human vascular endothelial cells (ECV 304) via the nitrobenzylthioinosine-insensitive equilibrative nucleoside transporter. Biochem J 317:843-848.

Pan G, Giri N, and Elmquist WF (2007) Abcg2/Bcrp1 mediates the polarized transport of antiretroviral nucleosides abacavir and zidovudine. Drug Metab Dispos 35:1165-1173.

Pfaffl MW (2001) A new mathematical model for relative quantification in real-time RT-PCR. Nucleic Acids Res 29:e45.

Radilova H, Libra A, Holasova S, Safarova M, Viskova A, Kunc F, and Buncek M (2009) COX-1 is coupled with mPGES-1 and ABCC4 in human cervix cancer cells. Mol Cell Biochem 330:131-140.

Sai Y, Nishimura T, Shimpo S, Chishu T, Sato K, Kose N, Terasaki T, Mukai C, Kitagaki S, Miyakoshi N, et al. (2008) Characterization of the mechanism of zidovudine uptake by rat conditionally immortalized syncytiotrophoblast cell line TR-TBT. Pharm Res 25:1647-1653.

Shaik N, Giri N, Pan G, and Elmquist WF (2007) P-glycoprotein-mediated active efflux of the antiHIV1 nucleoside abacavir limits cellular accumulation and brain distribution. Drug Metab Dispos 35:2076-2085.

Staud F and Ceckova M (2015) Regulation of drug transporter expression and function in the placenta. Expert Opin Drug Metab Toxicol 11:533-555.

Staud F, Cerveny L, and Ceckova M (2012) Pharmacotherapy in pregnancy; effect of ABC and SLC transporters on drug transport across the placenta and fetal drug exposure. $J$ Drug Target 20:736-763.

Thomas SH and Yates LM (2012) Prescribing without evidence - pregnancy. Br J Clin Pharmacol 74:691-697.

Tsujie M, Nakamori S, Nakahira S, Takahashi Y, Hayashi N, Okami J, Nagano H, Dono K, Umeshita K, Sakon M, et al. (2007) Human equilibrative nucleoside transporter 1, as a predictor of 5-fluorouracil resistance in human pancreatic cancer. Anticancer Res 27 (4B):2241-2249.

Utoguchi N, Chandorkar GA, Avery M, and Audus KL (2000) Functional expression of P-glycoprotein in primary cultures of human cytotrophoblasts and BeWo cells. Reprod Toxicol 14:217-224.

Yamamoto T, Kuniki K, Takekuma Y, Hirano T, Iseki K, and Sugawara M (2007) Ribavirin uptake by cultured human choriocarcinoma (BeWo) cells and Xenopus laevis oocytes expressing recombinant plasma membrane human nucleoside transporters. Eur J Pharmacol 557:1-8.

Address correspondence to: Frantisek Staud, Department of Pharmacology and Toxicology, Charles University, Faculty of Pharmacy in Hradec Kralove, Akademika Heyrovskeho 1203, Hradec Kralove, 50005 Czech Republic. E-mail: frantisek. staud@faf.cuni.cz 